\title{
A questionnaire-based evaluation of the veterinary cordon fence separating wildlife and livestock along the boundary of the Kruger National Park, South Africa
}

\author{
F. Jori ${ }^{\mathrm{a}, \mathrm{b}, \mathrm{e}, *}$, D. Brahmbhatt ${ }^{\mathrm{c}}$, G.T. Fosgate ${ }^{\mathrm{b}}$, P.N. Thompson ${ }^{\mathrm{b}}$, C. Budke ${ }^{\mathrm{c}}$, M.P. Ward ${ }^{\mathrm{c}, \mathrm{f}}$, \\ K. Ferguson ${ }^{\mathrm{e}}$, B. Gummow ${ }^{\mathrm{b}, \mathrm{d}}$ \\ a CIRAD, UR AGIRs, Campus International de Baillarguet, Montpellier 34392, France \\ b Section of Epidemiology, Department of Production Animal Studies, Faculty of Veterinary Science, University of Pretoria, Onderstepoort 0110, South Africa \\ c Department of Veterinary Integrative Biosciences, Texas AEM University, College Station, TX 77843, United States \\ d Present address: School of Veterinary and Biomedical Sciences, James Cook University, Townsville, Queensland 4811, Australia \\ e Present address: Mammal Research Institute, Department of Zoology, University of Pretoria, 0002, South Africa \\ ${ }^{f}$ Present address: Faculty of Veterinary Science, The University of Sydney, Camden, New South Wales 2570, Australia
}

\section{A R T I C L E I N F O}

\section{Article history:}

Received 6 June 2010

Received in revised form 29 March 2011

Accepted 30 March 2011

\section{Keywords:}

Fence

Control

Interface

Transmission

Wildlife

Infectious diseases

\begin{abstract}
A B S T R A C T
Veterinary cordon fences are used in Southern Africa to separate wildlife from domestic animals in order to prevent transmission of infectious diseases. Such fences are a control method recognized by the World Organization for Animal Health (OIE) for establishing disease-free zones in beef exporting countries. However, few studies have evaluated the ecological impact of these physical barriers or their effectiveness at a multispecies level. We examined the permeability of one such barrier, along $357 \mathrm{~km}$ of the western and southern boundary of the Kruger National Park (KNP) during 2007. Information was gathered using a semi-structured questionnaire implemented among 32 teams of fence maintenance workers. Data were analyzed to identify (a) the main causes of fence damage, (b) the seasonality, location and duration of fence repairs, (c) high permeability areas for elephant (Loxodonta africana), kudu (Tragelaphus strepsiceros), impala (Aepyceros melampus), buffalo (Syncerus caffer) and warthog (Phacochoerus africanus), and (d) the influence of fence electrification, rivers and elephant damage on the frequency of observation of wildlife species outside the KNP estimated during the year. Human and elephant damage were the most common reasons for fence repairs. Elephant and buffalo were the most and least common large mammal species reported observed outside the KNP(1076 and 162 reports/year), respectively. Cattle incursions into the KNP were also reported in $44 \%$ of the fence sections. Electrification of the fence was an important factor explaining differences in estimated wildlife species observations outside the KNP during the year. Correlations between estimations of observed species suggested that fence gaps created by elephants might be used by the other wildlife species. Estimated annual counts of kudu, impala and buffalo, but not warthog, were found to correlate with elephant observations. Negative binomial regression models were developed to explore the relationships between observed estimations of different wildlife species outside the KNP the fence, electrification of fence sections and the presence of watercourses, suggesting that kudu, impala and buffalo could use elephant induced fence damage to leave the KNP. The questionnaire was able to evaluate fence integrity and identify sections where integrity was sub-optimal for separating wildlife from domestic livestock species. If
\end{abstract}

* Corresponding author at: Mammal Research Institute, Department of Zoology and Entomology, University of Pretoria, 0002, South Africa. Tel.: +27 012420 2016; fax: +27 0124202534 .

E-mail address: ferran.jori@cirad.fr (F. Jori).

0167-5877/\$ - see front matter @ 2011 Elsevier B.V. All rights reserved. doi:10.1016/j.prevetmed.2011.03.015 
combined with more quantitative methods and applied on a routine basis, it could provide an efficient and cost-effective method for monitoring the effectiveness of physical barriers to contain wildlife within protected areas such as is the case with veterinary cordon fences in Southern Africa.

(c) 2011 Elsevier B.V. All rights reserved.

\section{Introduction}

Southern Africa is known for its abundance and diversity of large mammals, which are mostly concentrated in protected wildlife areas. These wildlife populations are infected by several important animal pathogens that can seriously impact animal production, beef exports and public health (Michel et al., 2006; Vosloo et al., 2002; Vosloo and Thomson, 2004). In an attempt to control the transmission of pathogens from wildlife to livestock and to mitigate human/wildlife conflict, many wildlife areas in Namibia (O’Conell-Rodwell et al., 2000), Botswana (Martin, 2005) and Zimbabwe (Sutmoller et al., 2000; Sutmoller, 2002) are bounded by thousands of kilometres of veterinary cordon fences (Thomson, 1999). This is also the case for the western and southern boundaries of the Kruger National Park (KNP), South Africa, which are enclosed by $750 \mathrm{~km}$ of fence. This fence was erected in 1960 to separate cattle from African buffaloes (Syncerus caffer), the natural reservoirs of foot-and-mouth disease (FMD) virus (Vosloo et al., 2002; Vosloo and Thomson, 2004). Since then, this fence has undergone several changes to improve its efficiency. However, its performance in fulfilling the goal of separating wildlife from livestock has never been systematically evaluated (R. Bengis, pers. comm.). The fence is exposed to various environmental and human pressures, including flooding, breaks due to wildlife movement, and damage due to component theft (Jori et al., 2009). However, very few studies have measured the importance of each of these factors on fence efficiency. Moreover, the magnitude of damage is not homogenous along the length of the fence. It is therefore necessary to identify which areas are at greater risk of damage and more likely to allow contacts between domestic animals and wildlife, so that fence maintenance and disease control measures can be more efficiently targeted. The goal of this study was to develop a method to identify factors affecting fence permeability along the western and southern border of KNP. Specifically, we aimed to (a) locate those sections of the fence that are more often damaged and therefore are more permeable to wildlife or domestic livestock; (b) identify the main causes of permeability in each section of the fence; (c) estimate the number of occasions on which large mammals of various species that cross the fence in each area; and (d) identify possible factors affecting their movement, including season, fence electrification, land use, rivers and elephant damage.

\section{Materials and methods}

\subsection{Location}

The KNP covers nearly $20,000 \mathrm{~km}^{2}$ of semi-arid savannah in the eastern Lowveld region of South Africa. It is bordered to the east by Mozambique and to the north by Zimbabwe. The western limit of the park crosses two South African provinces, Mpumalanga and Limpopo. Elevation ranges from 260 to $839 \mathrm{~m}$ above sea level and mean annual rainfall ranges from $750 \mathrm{~mm}$ in the south to $440 \mathrm{~mm}$ in the north, with large seasonal and annual variation. The western part of KNP is dominated by granitic soils and vegetation composition varies from heavily grazed grassy plains and savannah in the south to mopane (Colophospermum mopane) woodlands in the north.

The entire KNP fence from north to south spans $750 \mathrm{~km}$, of which $34 \%$ lies adjacent to private game reserves which are privately managed and 66\% lies adjacent to communal lands and private farms and is managed by the Department of Agriculture, Forestry and Fisheries (DAFF) of the South African Government (Fig. 1).

\subsection{Study design}

The $357 \mathrm{~km}$ of fence perimeter studied included $90 \%$ of the sections managed by DAFF. It was divided into three different geographic areas designated, from north to south, as A, B and C (Fig. 1). A summary of the characteristics of the fence sections included in this study is given in Table 1.

Area A, located along the northern part of the western boundary between Punda Maria and Phalaborwa, is $155 \mathrm{~km}$ long. It lies adjacent to communal pastoral land and the median proportion of fence electrified in this area is $24.6 \%$ [0\%, 58.3\%]. This portion of fence is crossed by 48 watercourses (including rivers and streams). The type of fence in this area is not uniform; it consists of four different types that vary in height, mesh type and age. Questionnaire data were obtained from 21 respondents (10 fence maintenance teams) in this area.

Area B consists of $101 \mathrm{~km}$ of the southern part of the western boundary, from Kruger Gate to Matsulu. It is bordered by communal pastoral land and the median proportion of fence electrified in this area is $53.6 \%[33 \%, 100 \%]$. This area is crossed by 95 watercourses. Questionnaire data were obtained from 14 respondents ( 8 fence maintenance teams) in this area.

Area $\mathrm{C}$, located along the southern boundary from Matsulu to Lebombo, is $122 \mathrm{~km}$ long. This perimeter is well electrified (the median proportion of electrified fence is $100 \%[98 \%, 100 \%])$, benefiting from the support of adjacent commercial fruit farms. This area is well watered, with a total of 112 watercourses of various sizes crossing the fence. Questionnaire data were obtained from 18 respondents (14 maintenance teams) in this area.

A further division was made according to sections of the fence serviced by each maintenance team. Each team 


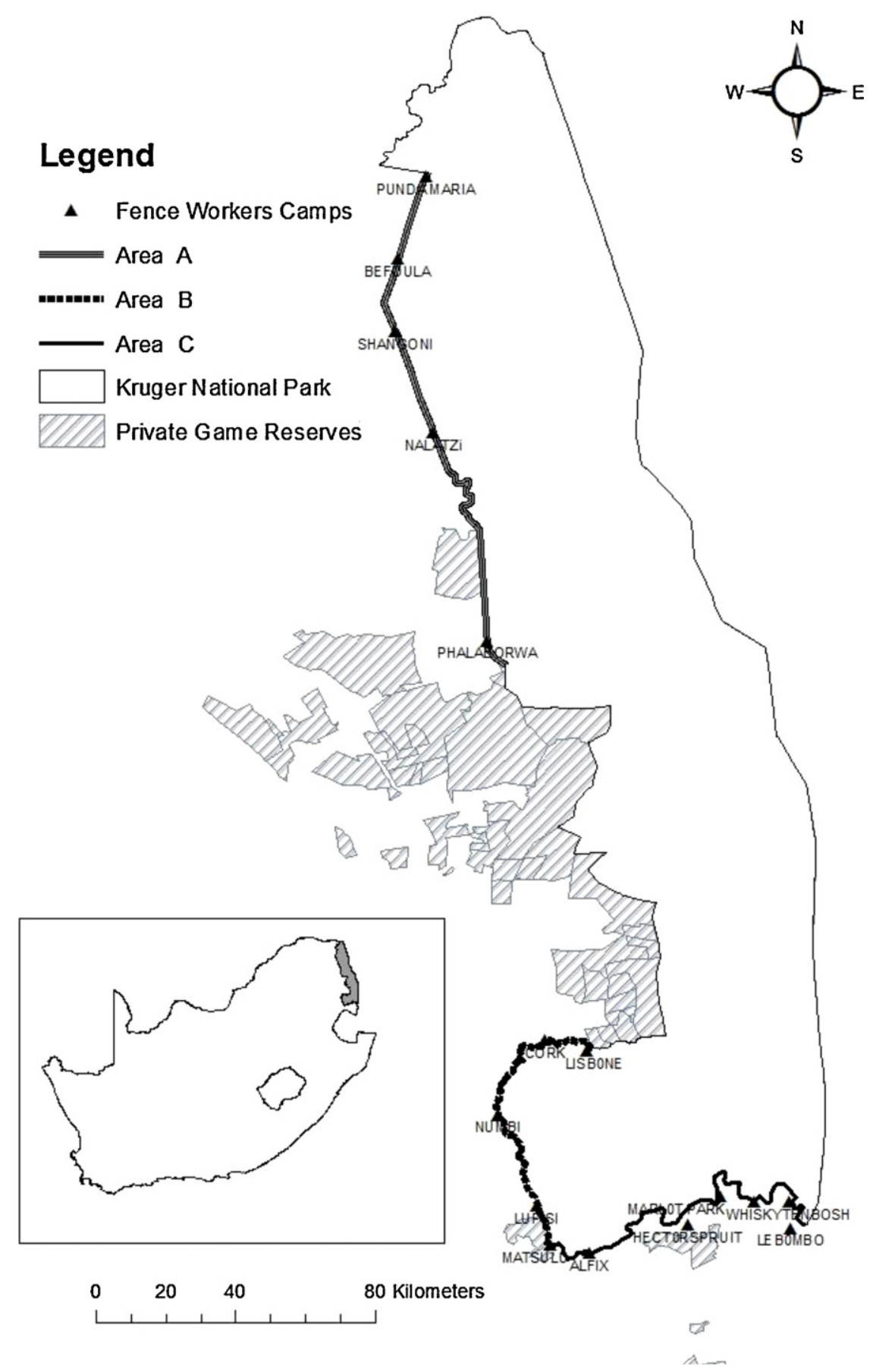

Fig. 1. Geographic location of the fence camps and the three study areas along the Kruger National Park boundary fence, South Africa.

maintains the fence for several kilometres on each side of their camp. Teams are employed by DAFF and are based in 16 camps along the fence. In this way the fence was divided into 32 sections, which served as the epidemiological unit for the risk factor analysis. Data were then gathered by means of an interview-based, semistructured questionnaire survey implemented among the 32 maintenance teams comprising a total of 54 fence workers.

\subsection{Questionnaire}

The questionnaire consisted of 80 questions and was designed to take an average of $25 \mathrm{~min}$ to complete. The template questionnaire was reviewed and corrected by experts in social sciences and epidemiology, modified, and approved by the Research Committee of the University of Pretoria, South Africa and the Institutional Review Board of Texas A\&M University. The questionnaire was tested in 
Table 1

Characteristics of the 32 sections of the Kruger National Park fence in the three geographical areas included in the study.

\begin{tabular}{|c|c|c|c|c|c|c|c|}
\hline Name of section & Rivers & $\begin{array}{l}\text { Number of } \\
\text { fence } \\
\text { workers }\end{array}$ & $\begin{array}{l}\text { Length } \\
(\mathrm{km})\end{array}$ & $\begin{array}{l}\text { Electrified } \\
\text { portion (\%) }\end{array}$ & $\begin{array}{l}\text { Type of } \\
\text { land use }\end{array}$ & $\begin{array}{l}\text { Type of } \\
\text { fence }\end{array}$ & Fence characteristics \\
\hline Punda North & 2 & 2 & 23 & 26.1 & Communal & 1 & Area A \\
\hline Punda South & 0 & 2 & 13 & 23.1 & Communal & 4 & $\begin{array}{l}\text { Number of sections }=10 \text { Median } \\
\text { length }=15 \mathrm{~km}[13,17]\end{array}$ \\
\hline Bevoula North & 0 & 2 & 11.7 & 59.8 & Communal & 1 & $\begin{array}{l}\text { Proportion of fence electrified: } \\
\text { Median }=0.246[0,0.583]\end{array}$ \\
\hline Bevoula South & 2 & 2 & 17 & 76.5 & Communal & 1 & Fence kinds: \\
\hline Shangoni North & 1 & 1 & 17 & 0 & Communal & 1 & $2.4 \mathrm{~m}$ high Electric fence (1) \\
\hline Shangoni South & 1 & 3 & 17 & 0 & Communal & 1 & 2,4 high diamond mesh (2) \\
\hline Naledzi north & 0 & 2 & 17 & 0 & Communal & 1 & 1,8 high rail cable ( 3$)$ \\
\hline Naledzi South & 0 & 2 & 13 & 0 & Communal & 3 & New I beam fence (4) \\
\hline Phalaborwa North & 0 & 2 & 13 & 100 & Communal & 2 & \\
\hline Phalaborwa South & 0 & 3 & 13 & 53.8 & Communal & 1 & \\
\hline Lisbon & 3 & 2 & 15 & 33.3 & Communal & 1 & Area B \\
\hline Cork North & 1 & 1 & 10 & 100 & Communal & 1 & $\begin{array}{l}\text { Number of sections }=8 \text { Median } \\
\text { length }=10.5 \mathrm{~km}[10,13]\end{array}$ \\
\hline Cork south & 2 & 1 & 20 & 25 & Communal & 1 & $\begin{array}{l}\text { Proportion of fence electrified: } \\
\text { Median }=0.536[0.33,1]\end{array}$ \\
\hline Phabeni & 2 & 1 & 15 & 100 & Communal & 1 & \\
\hline Numbi & 3 & 2 & 11 & 57.1 & Communal & 1 & \\
\hline Makoko & 2 & 3 & 10 & 100 & Communal & 1 & \\
\hline Luphisi & 3 & 2 & 10 & 50 & Communal & 1 & \\
\hline Matsulu & 0 & 2 & 10 & 30 & Communal & 1 & \\
\hline Alfix & 5 & 1 & 8.6 & 69.8 & Private & 1 & Area C \\
\hline Althorpe & 5 & 2 & 6.9 & 100 & Private & 1 & $\begin{array}{l}\text { Number of sections }=14 \text { Median } \\
\text { length }=10 \mathrm{~km}[6.9,11]\end{array}$ \\
\hline TBS & 2 & 1 & 2.6 & 100 & Private & 1 & $\begin{array}{l}\text { Proportion of fence electrified: } \\
\text { Median }=1[0.98,1]\end{array}$ \\
\hline Riverside & 1 & 1 & 14 & 100 & Private & 1 & \\
\hline Hectorspruit & 2 & 2 & 5.3 & 100 & Private & 1 & \\
\hline Hectorspruit & 3 & 2 & 9 & 55.6 & Private & 1 & \\
\hline Marloth Park & 0 & 1 & 11.7 & 94 & Private & 1 & \\
\hline Marloth Park & 0 & 1 & 11 & 100 & Private & 1 & \\
\hline Vadwal & 2 & 1 & 11.2 & 98.2 & Private & 1 & \\
\hline Martinlenhoud & 0 & 1 & 11 & 100 & Private & 1 & \\
\hline Whisky & 1 & 2 & 7 & 100 & Communal & 1 & \\
\hline Tenbosch West & 0 & 1 & 11 & 100 & Private & 1 & \\
\hline Tenbosch East & 2 & 1 & 11 & 100 & Private & 1 & \\
\hline Lebombo & 0 & 1 & 2 & 100 & Private & 1 & \\
\hline
\end{tabular}

the field with the assistance of 4 fence workers before final implementation.

The questions were grouped into four sections. The first section was designed to collect data from each team on: (1) ecological and structural characteristics of the fence; (2) the number, frequency and timing of incidents causing damage to the structure of the fence; and (3) the maximum, "average" and minimum time (h) taken to repair those damages. Fence damage was defined as a breach big enough for a large mammal (the size of a buffalo) to pass through. The second section collected data on the relative importance of various causes of fence damage, namely elephants, humans, predation (the result of animals being chased against the fence by predators), flooding, and mammals digging under the fence. Respondents were asked to rank the three most important causes of fence damage. The third section of the questionnaire recorded, by season (summer/winter), an estimate of the number of occasions on which various wildlife species were observed beyond the fence, outside the KNP, and any observed contact with livestock. Each fence worker or team was asked to estimate, retrospectively, the number of times per season that each species had been observed during the previous year and the smallest, average and largest herd size for every species. One sighting of a particular species, whether of an individual or a herd, counted as one observation. We estimated that the area of adjacent land visible from the KNP fence for wildlife observations ranged between 5 and $300 \mathrm{~m}$ depending on the predominant vegetation. The wild animal species considered were the large herbivores known to be more regularly observed in communal lands or which were more likely to be infected by infectious diseases transmissible by direct contact to cattle, namely elephant (Loxodonta africana), buffalo, impala (Aepyceros melampus), kudu (Tragelaphus strepsiceros) and warthog (Phacochoerus africanus). The fourth section recorded the observation of domestic animals inside the KNP. The domestic animal species considered were cattle, pigs, goats and sheep. Land use outside the KNP adjacent to each fence section was classified as being communal land or commercial farming, depending on the presence of settlements of rural communities or private farmland.

The questionnaire was administered during October 2007 and questions referred to the period between October 2006 and October 2007. Fifteen questionnaires were 
answered collectively by the fence worker team (47\%), usually consisting of 2 persons ( $n=15)$, except in 3 cases when there were 3 persons. Fourteen questionnaires (44\%) were answered by a single person.

\subsection{Analysis}

Within each section, causes of fence damage were assigned ranking scores as follows: 3 for the most important cause; 2 for the second-ranked cause; 1 for the third-ranked cause; 0 for causes not mentioned. A mean ranking score was then calculated for each cause of fence damage.

Each fence section was classified as either $\geq 90 \%$ or $<90 \%$ electrified, since we assumed that, if electrification is a deterrent to animals, then the entire length, or very nearly the entire length of the section would need to be electrified in order for it to be effective. Medians of outcome variables (total numbers of observations of elephant, buffalo, impala, kudu and warthog) were compared between categories of independent variables using the Wilcoxon rank-sum test (electrification; presence or absence of rivers; private or communal land use) or the Kruskal-Wallis one-way ANOVA on ranks (geographic area) for unmatched data, and the Wilcoxon signed-rank test for matched data (season). Associations among independent variables were assessed using the Wilcoxon rank-sum test or the Fisher's exact test, as appropriate. Spearman rank correlation was used to determine the pairwise associations between estimated counts of each wildlife species observed outside the KNP.

Negative binomial regression was used to model the number of reported observations of each of the 5 species observed outside the KNP. Separate models were fit to the total count, summer count and winter count of each species. The predictors of interest were rivers (present or absent), land use (private or communal) and electrification of the fence section $(<90 \%$ or $\geq 90 \%$ ). However, since land use and electrification were highly associated (fence sections adjoining private land were usually electrified and those adjoining communal land were seldom electrified; $P<0.001$ ), land use was not included in the negative binomial regression models to prevent collinearity. The natural logarithm of the length of each fence section was used as an offset in the models (i.e., section length was included with coefficient constrained to 1 ), on the assumption that, all other factors being equal, the expected counts of animal observations should be directly proportional to the length of the fence section. In addition, to determine whether elephants were a confounder of the relationship between other species and predictor variables (watercourses, fence electrification), a dichotomous variable (presence or absence of elephants) was then included as an additional covariate in each of the species-specific (buffalo, impala, kudu and warthog) models, and changes in the coefficients were noted. The presence of overdispersion in the models (i.e., justification for using negative binomial rather than Poisson regression) was tested using a likelihood ratio test comparing each model to the corresponding Poisson model. Model fit was assessed using the deviance $\chi^{2}$ goodness-of-fit test. A level of significance of $\alpha=0.05$ was used in all analyses.

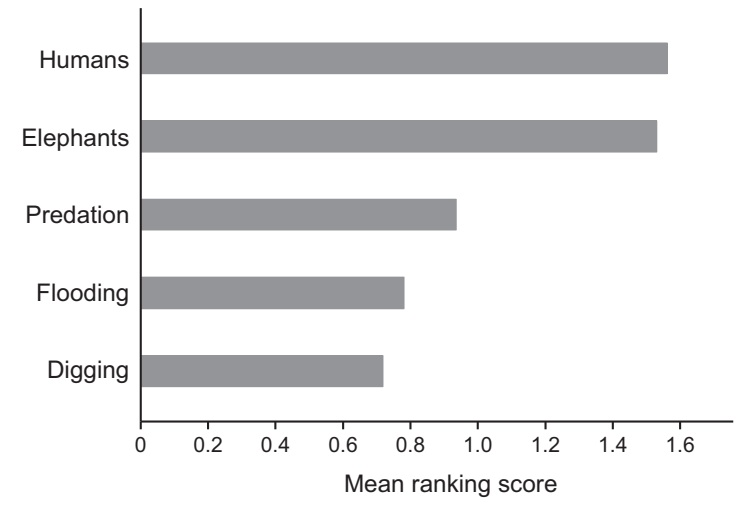

Fig. 2. Relative importance of the most common causes of damage to the Kruger National Park boundary fence, 2006-2007.

Data were analyzed using STATA 11.0 (StataCorp, College Station, TX, U.S.A.) and NCSS 2007 (NCSS, Kaysville, UT, U.S.A.).

\section{Results}

\subsection{Descriptive data}

The fence sections differed from each other in terms of length (Table 1), fence structure (different types of fences were present in the different sections), allocated resources (number of persons working per section) and surrounding land use. Forty-one percent of the sections were adjacent to private farms and $59 \%$ were adjacent to communal land.

\subsection{Fence repairs}

The median [interquartile range (IQR)] of the reported "average" repair time after discovery of a fence gap was $2 \mathrm{~h}[1,3]$. The median maximum time needed for repairing a gap was $24 \mathrm{~h}[4,48]$, and in $84 \%$ of the cases it did not exceed $48 \mathrm{~h}$. The median minimum time needed was $1 \mathrm{~h}[0.5,1]$. Seasonal differences between "average" repair times (summer $=30 \mathrm{~h}[11.5,72]$, winter $=19 \mathrm{~h}[12,36])$ were significant $(P=0.015)$.

\subsection{Causes of fence incidents}

Causes of fence incidents were ranked in order of importance (Fig. 2). Elephant and human activities were identified as the two most important causes of fence damage by the majority of the fence workers, followed by predation, flooding and animals digging under the fence (mostly warthogs and carnivores). By study area, there were differences in the ranking of those causes. Elephant damage was reported to happen "very often" (78\% of respondents) in area A and only seldom (45\%) in area C. Predation was reported as an "important" cause of damage in areas B and C (38\% and 57\%, respectively) while it was not reported at all in area A. For the other reported causes (i.e., animals digging, flooding or human damage), no differences between areas were detected. 
Table 2

Median [interquartile range] and (mean) of numbers of observations of various wildlife species crossing the boundary fence of the Kruger National Park over a one year period.

\begin{tabular}{|c|c|c|c|c|c|c|c|}
\hline Variable & Level & $n$ & Elephant & Buffalo & Impala & Kudu & Warthog \\
\hline \multirow[t]{3}{*}{ Electrification } & $\geq 90 \%$ & 14 & $0[1,36](2.3)$ & $0[1,11](2.0)$ & $0[0,12](1.1)$ & $0[0,12](2.0)$ & $0[0,24](14)$ \\
\hline & $<90 \%$ & 18 & $12[0,0](58)$ & $6[0,1](6.8)$ & $3[0,0](20)$ & $1[0,1](27)$ & $0[0,0](25)$ \\
\hline & $P^{\mathrm{a}}$ & & 0.001 & 0.003 & 0.010 & 0.071 & 0.131 \\
\hline \multirow[t]{3}{*}{ Land use } & Private & 13 & $0[0,0](0.2)$ & $0[0,1.5](2.3)$ & $0[0,0](1.2)$ & $0[0,0](0.3)$ & $0[0,0](1.0)$ \\
\hline & Communal & 19 & $18[1,36](57)$ & $3[1,12](6.1)$ & $1[0,12](18)$ & $1[0,12](27)$ & $0[0,36](32)$ \\
\hline & $P^{\mathrm{a}}$ & & $<0.001$ & 0.026 & 0.015 & 0.019 & 0.041 \\
\hline \multirow[t]{3}{*}{ River(s) } & Present & 20 & $0.5[0,15](25)$ & $6[0,12](5.6)$ & $0[0,12](16)$ & $0.5[0,12](25)$ & $0[0,12](17)$ \\
\hline & Absent & 12 & $1[0,27](48)$ & $1[0,3](3.1)$ & $0[0,5](3.9)$ & $0[0,1](0.8)$ & $0[0,1](24)$ \\
\hline & $P^{\mathrm{a}}$ & & 0.622 & 0.285 & 0.689 & 0.169 & 0.800 \\
\hline \multirow[t]{3}{*}{ Season } & Summer & 32 & $0.5[0,15](23)$ & $0[0,3](2.3)$ & $0[0,3](9)$ & $0[0,1.5](7.6)$ & $0[0,0](14)$ \\
\hline & Winter & 32 & $0[0,6](11)$ & $0[0,2](2.4)$ & $0[0,2](2.2)$ & $0[0,0](8.3)$ & $0[0,0](6.4)$ \\
\hline & $P^{\mathrm{b}}$ & & 0.001 & 0.949 & 0.138 & 0.129 & 0.611 \\
\hline \multirow[t]{4}{*}{ Area } & A (North) & 10 & $33[24,186](103)$ & $4.5[3,12](8.1)$ & $3.5[0,12](22)$ & $1.5[0,12](39)$ & $0[0,78](40)$ \\
\hline & B (Southwest) & 8 & $1.5[0.5,4](5.3)$ & $3.5[1,7](4.4)$ & $0.5[0,27](14)$ & $1[0,21](12)$ & $0.5[0,13](26)$ \\
\hline & C (South) & 14 & $0[0,0](0.1)$ & $0[0,1](2.2)$ & $0[0,0](1.2)$ & $0[0,1](2)$ & $0[0,0](0.9)$ \\
\hline & $P^{\mathrm{c}}$ & & $<0.001$ & 0.030 & 0.065 & 0.184 & 0.080 \\
\hline
\end{tabular}

\footnotetext{
a Wilcoxon rank-sum test.

b Wilcoxon signed-rank test.

c Kruskal-Wallis one-way ANOVA on ranks.
}

\subsection{Observations of wildlife outside the KNP}

Wildlife species were observed outside the KNP in $82 \%$ of the fence sections. The species more frequently reported were elephant (reported 1076 times during the year of the study), followed by warthog (621 times), kudu (511 times), impala (348 times) and buffalo (162 times). There was seasonal variation, with more elephant observations in summer than in winter $(P=0.001)$; differences for other species were not statistically significant, although impala were also more frequently observed in summer. There were significant differences in the counts of wildlife observations for areas B vs. C $(P=0.05)$ and A vs. C $(P=0.002)$ (Table 2$)$. When counts were compared between the different areas for each species, significant differences were found only for buffalo (A vs. C; $P=0.04$ ) and elephant (A vs. $C ; P<0.01$ ). For each species, the highest, mode and minimum number of individuals observed at one particular time are shown in Table 3 . The median group size ranged between 1 and 2, the largest groups of animals observed at one point in time being elephants $(n=20)$ and impala $(n=20)$.

Crude associations between the estimated counts of wildlife observations outside the KNP fence and electrification, land use, rivers, season and study area are shown in Table 2. The counts of all wildlife species outside the KNP were consistently higher for fence sections adjacent to communal land than adjacent to private farms. Estimated counts of elephant, buffalo and impala observations were significantly higher adjacent to sections that were $<90 \%$ electrified compared to those that were $\geq 90 \%$ electrified. Although not significant, the total number of fence repairs was two-fold higher in areas with rivers (20 vs. 10), and the median time for repairing the fence was also higher in those areas (3.2 h vs. $2.1 \mathrm{~h}$ ). Damage to the fence due to flooding or predation was reported to be higher in areas with rivers ( $75 \%$ and $50 \%$, respectively) than in areas without rivers ( $17 \%$ and $8 \%$, respectively).

Cattle were reported to have been seen entering the KNP in $38 \%(12 / 32)$ of the sections studied and in 63\% (12/19) of the sections adjacent to communal land. All cattle incursions into the KNP were reported adjacent to communal land areas, 58\% (7/12) occurring in area B and 42\% (5/12) in area A. Other livestock reported inside the KNP were small ruminants in $16 \%(5 / 32)$ of the sections.

\subsection{Correlation between observation of elephants and other species}

All the pairwise correlations between the counts of elephant, buffalo, impala and kudu observations were significant $(P<0.02)$, with Spearman's $r$ ranging between 0.42 and 0.58 (Table 4$)$. No significant $(P>0.28)$ correlation was found between warthog and any other species.

\subsection{Multivariable analysis}

Electrification and land use were strongly associated and only electrification was used in the final models (Table 5). All models showed adequate fit and the tests for overdispersion were highly significant. There was a strong negative association between the estimated counts of elephants and fence electrification (count ratio $[\mathrm{CR}]=0.02$;

Table 3

Maximum, most frequent and minimum group sizes of various wildlife species observed by fence workers outside the Kruger National Park during 2007.

\begin{tabular}{|c|c|c|c|c|}
\hline & Minimum & Mode & Maximum & No. of responses \\
\hline Buffalo & 1 & 2 & 8 & 29 \\
\hline Elephant & 1 & 3 & 20 & 20 \\
\hline Impala & 1 & 3 & 20 & 19 \\
\hline Kudu & 1 & 2 & 8 & 13 \\
\hline Warthog & 2 & 2 & 4 & 11 \\
\hline
\end{tabular}


Table 4

Correlation (Spearman's $r$ ) between counts of observations of various wildlife species outside the Kruger National Park fence over a one year period.

\begin{tabular}{lllll}
\hline Species & Elephant & Buffalo & Impala & \\
\hline Elephant & 1.000 & & & \\
Buffalo & $0.549 P=0.001$ & 1.000 & 1.000 & \\
Impala & $0.521 P=0.003$ & $0.422 P=0.018$ & $0.576 P<0.001$ & 1.000 \\
Kudu & $0.460 P=0.009$ & $0.435 P=0.015$ & $0.158 P=0.396$ & $0.047 P=0.801$ \\
Warthog & $0.201 P=0.280$ & $-0.069 P=0.713$ & 1.000 \\
\hline
\end{tabular}

Table 5

The association of fence electrification and watercourses with numbers of observations of wildlife crossing the KNP boundary fence over a one year period, presented as count ratios, with and without controlling for elephant observations: results of negative binomial regression models.

\begin{tabular}{|c|c|c|c|c|c|c|}
\hline Outcome and predictors & Count ratio & $95 \% \mathrm{CI}$ & $P$ & Count ratio & $95 \% \mathrm{CI}$ & $P$ \\
\hline Elephants & \multicolumn{6}{|l|}{$\left(\right.$ Model 1) ${ }^{a}$} \\
\hline Fence $\geq 90 \%$ electrified & 0.023 & $0.003,0.155$ & $<0.001$ & - & & \\
\hline River(s) present & 0.149 & $0.022,1.014$ & 0.052 & - & & \\
\hline Other Species & \multirow{2}{*}{\multicolumn{3}{|c|}{$\begin{array}{l}\text { No controlling for elephants } \\
(\text { Model } 2)^{b}\end{array}$}} & \multirow{2}{*}{\multicolumn{3}{|c|}{$\begin{array}{l}\text { Controlling for elephants } \\
\left(\text { Model 3) }{ }^{\mathrm{c}}\right.\end{array}$}} \\
\hline Buffalo & & & & & & \\
\hline Fence $\geq 90 \%$ electrified & 0.512 & $0.161,1.621$ & 0.255 & 1.009 & $0.145,7.041$ & 0.993 \\
\hline River(s) present & 1.897 & $0.585,6.154$ & 0.286 & 2.208 & $0.647,7.541$ & 0.206 \\
\hline Elephant(s) seen crossing & - & & & 2.346 & $0.307,17.90$ & 0.411 \\
\hline Impala & \multicolumn{3}{|l|}{$\left(\right.$ Model 4) ${ }^{d}$} & \multicolumn{3}{|l|}{$\left(\right.$ Model 5) ${ }^{\mathrm{e}}$} \\
\hline Fence $\geq 90 \%$ electrified & 0.082 & $0.011,0.612$ & 0.015 & 0.458 & $0.000,557.9$ & 0.830 \\
\hline River(s) present & 0.862 & $0.111,6.717$ & 0.887 & 0.864 & $0.114,6.547$ & 0.888 \\
\hline Elephant(s) seen crossing & - & & & 5.974 & $0.005,6738$ & 0.618 \\
\hline Kudu & \multicolumn{3}{|l|}{$\left(\right.$ Model 6) ${ }^{f}$} & \multicolumn{3}{|l|}{$($ Model 7) $\mathrm{g}$} \\
\hline Fence $\geq 90 \%$ electrified & 0.231 & $0.035,1.525$ & 0.128 & 8.147 & $0.182,365.4$ & 0.280 \\
\hline River(s) present & 17.86 & $2.329,137.0$ & 0.006 & 40.36 & $5.493,296.5$ & $<0.001$ \\
\hline Elephant(s) seen crossing & - & & & 76.23 & $1.439,4037$ & 0.032 \\
\hline Warthogs & \multicolumn{3}{|l|}{$\left(\right.$ Model 8) ${ }^{\mathrm{h}}$} & \multicolumn{3}{|l|}{$\left(\right.$ Model 9) ${ }^{\mathrm{i}}$} \\
\hline Fence $\geq 90 \%$ electrified & 0.194 & $0.004,8.923$ & 0.401 & 0.194 & $0.004,9.877$ & 0.414 \\
\hline River(s) present & 0.252 & $0.005,12.60$ & 0.490 & 0.255 & $0.001,52.40$ & 0.615 \\
\hline Elephant(s) seen crossing & \multicolumn{3}{|l|}{-} & 1.011 & $0.017,59.81$ & 0.996 \\
\hline
\end{tabular}

a LRT vs. Poisson model: $P<0.001$; deviance $\chi^{2}$ goodness-of-fit test: $\chi^{2}=29.1,29 \mathrm{df}, P=0.459$.

b LRT vs. Poisson model: $P<0.001$; deviance $\chi^{2}$ goodness-of-fit test: $\chi^{2}=32.7,28 \mathrm{df}, P=0.249$.

c LRT vs. Poisson model: $P<0.001$; deviance $\chi^{2}$ goodness-of-fit test: $\chi^{2}=32.4,27 \mathrm{df}, P=0.216$.

${ }^{d}$ LRT vs. Poisson model: $P<0.001$; deviance $\chi^{2}$ goodness-of-fit test: $\chi^{2}=25.9,28 \mathrm{df}, P=0.577$.

e LRT vs. Poisson model: $P<0.001$; deviance $\chi^{2}$ goodness-of-fit test: $\chi^{2}=26.2,27 \mathrm{df}, P=0.510$.

${ }^{\text {f }}$ LRT vs. Poisson model: $P<0.001$; deviance $\chi^{2}$ goodness-of-fit test: $\chi^{2}=26.8,29 \mathrm{df}, P=0.581$.

g LRT vs. Poisson model: $P<0.001$; deviance $\chi^{2}$ goodness-of-fit test: $\chi^{2}=25.1,28 \mathrm{df}, P=0.624$.

${ }^{\text {h }}$ LRT vs. Poisson model: $P<0.001$; deviance $\chi^{2}$ goodness-of-fit test: $\chi^{2}=18.1,28 \mathrm{df}, P=0.924$.

${ }^{i}$ LRT vs. Poisson model: $P<0.001$; deviance $\chi^{2}$ goodness-of-fit test: $\chi^{2}=18.1,27 \mathrm{df}, P=0.901$.

$P<0.001$ in Model 1); for other species CRs were also $<1$, although the association was $\operatorname{significant}(P=0.015)$ only for impala (Model 4) and not significant for buffalo, kudu or warthog. However, the addition of elephants as a predictor in the buffalo, impala and kudu models resulted in considerable changes to, and reduction in the significance of, the estimated CR for electrification; for buffalo the CR became
1.0 (Models 2 and 3), for impala it changed towards the null (Models 4 and 5), and for kudu the direction of effect was reversed (Models 6 and 7). For warthogs, the addition of elephants resulted in no change to the estimated CR for electrification (Models 8 and 9). The association between the presence of rivers and counts of wildlife observations was highly significant for kudu, with higher counts in areas

Table 6

Median, [IQR] and numbers of observations ( $\mathrm{n}$ ) of buffalo, kudu and impala crossing the fence, depending on fence electrification and whether elephants were also seen crossing.

\begin{tabular}{|c|c|c|c|}
\hline & \multicolumn{2}{|c|}{ Elephant(s) observed crossing } & \multirow[t]{2}{*}{ Total } \\
\hline & Yes & No & \\
\hline \multicolumn{4}{|c|}{ Fence $\geq 90 \%$ electrified } \\
\hline \multirow[t]{3}{*}{ Yes } & Buffalo: $0[0,1](3)$ & Buffalo: 0 [0,2] (11) & Buffalo: $0[0,1](14)$ \\
\hline & Impala: $0[0,0](3)$ & Impala: $0[0,1](11)$ & Impala: $0[0,0](14)$ \\
\hline & Kudu: $0[0,1](3)$ & Kudu: $0[0,1](11)$ & Kudu: $0[0,1](14)$ \\
\hline \multirow[t]{3}{*}{ No } & Buffalo: $6[3,12](14)$ & Buffalo: $0[0,7](3)$ & Buffalo: $6[1,12](17)$ \\
\hline & Impala: 5 [1,24] (14) & Impala: $0[0,0](3)$ & Impala: $3[0,12](17)$ \\
\hline & Kudu: $3.5[0,12](14)$ & Kudu: $0[0,0](4)$ & Kudu: $1[0,12](18)$ \\
\hline \multirow[t]{3}{*}{ Total } & Buffalo: $3[1,12](17)$ & Buffalo: $0[0,2](14)$ & Buffalo: $1[0,7](31)$ \\
\hline & Impala: 3 [0,12] (17) & Impala: $0[0,0](14)$ & Impala: $0[0,6](31)$ \\
\hline & Kudu: $1[0,12](17)$ & Kudu: $0[0,0](15)$ & Kudu: 0 [0,3.5] (32) \\
\hline
\end{tabular}


with rivers ( $C R=40 ; P<0.001$ ) (Model 7). Elephants, however, were less frequently observed in such areas $(C R=0.15$; $P=0.05$ ) (Model 1). Descriptively, the observations of other wildlife were highest for fence sections without electrification in which elephants were also observed (Table 6).

The negative binomial regression models fit separately for summer and winter counts of each species are not presented, since they showed essentially the same results as above. The only differences were that the negative associations between fence electrification and wildlife counts were stronger and more significant for impala during the summer $(C R=0.02 ; P<0.001)$ and for kudu during the winter $(C R=0.01 ; P=0.006)$. For impala, the significant association was removed with the addition of elephants to the model ( $C R=0.7 ; P=0.87)$; and for kudu its magnitude was reduced, but it remained significant $(C R=0.02$; $P=0.02$ ).

\section{Discussion}

Veterinary fences are commonly used to separate livestock from wildlife in southern Africa. This method is accepted by the World Organization for Animal Health (OIE) as one of the methods of establishing FMD diseasefree zones in Southern Africa and is widely implemented by beef exporting countries such as South Africa, Namibia and Botswana to preserve their disease-free status (Thomson, 1999; O'Conell-Rodwell et al., 2000; Martin, 2005; Jori et al., 2009; Thomson et al., 2003). However, the extent to which they achieve the objective of separating wildlife from livestock has rarely been investigated and reports of methods to evaluate their effectiveness are absent from the literature. This study presents the results of a semi-quantitative method to monitor the effectiveness of such a fence in deterring wildlife from exiting the KNP and for comparing wildlife pressure between the different fence sections.

Elephant and human activities were the major causes of fence damage (Fig. 2); the former being particularly important in area A. Elephants were more likely to cross the fence in summer than in winter. This is consistent with previous reports on elephant movements out of the park in late summer (February-April). A possible explanation for this could be related to the elephants' attraction to the fruit of the marula tree (Sclerocarya birrea), that grows more abundantly outside the fence boundaries (Gadd, 2002; Grant et al., 2008). Fewer buffalos were seen outside the fence than other large mammal species. This makes ecological sense because non-buffalo species are able to cross the fence more easily by (a) jumping over the fence in the case of antelopes (Hargreaves et al., 2004), (b) digging under the fence in the case of warthogs (Schumann et al., 2006) or (c) walking through non-electrified fences in the case of elephants (Thouless and Sakwa, 1995).

Predation was also an important cause of fence damage in sections that lie in more well-watered areas (areas $B$ and $C$ ). In the absence of predators, animals apart from elephants are unlikely to cause significant physical damage to the fence, and therefore electrification is unlikely to strongly influence fence crossing. Nevertheless, significant differences in counts of not only elephant, but also buffalo and antelope observations outside the KNP between electrified and non-electrified fence sections, suggest that maintenance of electrification on the fence had an influence on the numbers of these species that were able to cross the fence. The Spearman coefficients presented in Table 4 show that the observation of elephants outside the KNP was positively correlated with that of other species. This association was further confirmed by the large changes in the negative binomial regression coefficients for electrification in the case of buffalo, kudu and impala when the models were adjusted for elephants (Table 5), indicating that elephant observation was a confounder. The potential role of elephants as a confounder is further supported by the increased $P$ value for the effect of electrification when elephants were included in the models. Furthermore, Table 6 shows an increase in the counts of observations of the other species in areas where electrification was poor, but this is obvious only in sections where elephants were also observed outside the fence, and negligible in sections where no elephants were observed. Elephants therefore also appear to be acting as a modifier of the effect of electrification on the counts of other species. Due to the small sample size this may be difficult to interpret; in particular, there were very few instances in which elephants were observed crossing in well electrified sections, or where no elephants were observed crossing in poorly electrified sections. The small sample size also made it unfeasible to include interaction terms in the regression models.

Sutmoller et al. (2000) reported that it takes several days for buffalo to use a fence gap, once they have been accustomed to the presence of a physical barrier for a certain period of time, and that they would be unlikely to cross that gap during the first $24 \mathrm{~h}$. We found that in $84 \%$ of fence sections, the maximum time taken to repair the fence was less than $48 \mathrm{~h}$. Thus, we expected that buffalo would not commonly make use of elephant damage to the fence to escape from the KNP. However, the correlation of elephant counts with those of buffalo, kudu and impala, along with the evidence for a confounding and modifying effect of elephants on the apparent association between fence electrification and observed counts of buffalo, kudu and impala, suggest strongly that fence damage caused by elephants could be one of the main reasons for the escape of other wildlife species, including buffalo. In contrast, fence electrification was not associated with observations of warthogs outside the fence, warthog counts were not significantly associated with those of other species, and the warthog model was unaffected by adjustment for elephant observations outside the fence (Table 5, Models 8 and 9). This is consistent with the behaviour of warthogs, digging under fences (Schumann et al., 2006) and therefore being less dependent on elephant-induced damage in order to cross the fence.

Fence permeability in our study was associated with the electrification of the fence, which is linked with the level of fence maintenance. The strong association detected between fence electrification and land use also suggests that the degree of fence maintenance differs depending on whether it is publicly or privately owned. The link between wildlife deterrence, electrification and fence maintenance has been described by others (O'Conell-Rodwell et al., 2000; Okello and D'Amour, 2008). Since electrical power maintenance is much poorer in communal lands (solar pan- 
els and generators are often stolen), wildlife observations outside the KNP were higher in these areas. Both factors (fence electrification and land use) were highly associated and their association with wildlife figures could not be analyzed in the same model. However, fence electrification is more likely to be a causal factor since land use can also be influenced by other factors that also affect wildlife presence, such as crop types and human population density.

The epidemiological significance of animal movements through the fence lies in the potential for contacts between domestic and wild species and the subsequent transmission of pathogens. Indeed, relatively small numbers of buffalo were observed crossing the fence, compared to other wildlife species monitored. However, buffalo are able to transmit a variety of diseases to livestock and their epidemiological impact in terms of disease transmission is likely to be more important than in the case of elephants. For example, at least five outbreaks of FMD related to buffalo have been reported between 2000 and 2007 (Thomson et al., 2003; Jori et al., 2009). Impala (Vosloo et al., 2006; Jori et al., 2009) and kudu (Letshwenyo et al., 2006; Vosloo et al., 2006; Anderson et al., 1993) are also potentially able to transmit FMD virus to other species and are reported to represent an epidemiological risk, should contacts with cattle occur (Vosloo et al., 2009). Those contacts between domestic and wild animals are very difficult to measure in the dynamics of cross species transmission of infectious diseases. Contacts might occur depending on the time that wildlife species from the KNP remain in communal lands and on their ability to return to the KNP when disturbed or chased by people or domestic animals. Elephants easily manage to find their way back through the fence if it is not properly electrified. Buffalo are often chased back into the KNP by veterinary authorities. The time necessary to undertake these operations is variable and depends on the time elapsed before buffalo are spotted and the level of coordination between the different teams involved. Despite most of the livestock in communal lands being corralled at night (Jori et al., 2009), buffalo can remain outside the KNP for several days and contact with cattle can therefore occur during the day in common grazing areas, allowing the possible transmission of pathogens by direct contact. Smaller game such as antelope and warthogs are likely to be chased by dogs and hunted if they do not quickly find their way back to the park (R. Bengis, pers. comm.).

Cattle incursions into the KNP are also likely to be important due to the potential for contact with wildlife. Our study suggests that cattle entered the KNP in $44 \%$ of the fence sections, compared to $88 \%$ of fence sections where wildlife was observed outside the KNP. However, cattle entering the park is not an isolated event, an observation confirmed by other questionnaires implemented among rangers inside the KNP (Brahmbhatt et al., 2009). While occasional wildlife-cattle contacts within the KNP should not present a risk for FMD transmission (if cattle in the area are regularly vaccinated and the vaccine provides adequate protection), they represent a risk for domestic animals contracting other diseases from wildlife, such as theileriosis (Potgieter et al., 1988; Latif et al., 2002). In addition, it also represents a risk for wildlife contracting pathogens from domestic animals. This has occurred in the past, when con- tacts between buffalo and cattle on the KNP boundaries resulted in the transmission of Mycobacterium bovis to buffalo (Kloeck, 1998). This disease has now become a major wildlife health problem in the park, particularly for endangered species (Michel et al., 2006).

The presence of rivers and smaller watercourses crossing the fence may play a role in the number of animals crossing the fence trying to escape from predators. A possible explanation is that areas with a higher number of watercourses (area $C$ for instance) host a higher abundance of prey and predators. In these areas, predators (such as lions) ambush animals against the fence more frequently (R. Bengis, pers. comm.). This is shown by the increased importance of predation as an identified cause of observed fence damage in more well-watered areas. A second explanation is that damage to the fence caused by flooding is more severe in areas with watercourses, as suggested by the increased estimated average time needed to repair fence gaps in those areas. Nevertheless, in our study we did not find a significant association between the presence or absence of watercourses and the number of animals escaping, except in the case of kudu which were more commonly observed in sections where rivers were present. This may be due to the small sample size in this study, or because animal abundance is also influenced by other factors such as soil quality, vegetation type or carrying capacity, which were not considered in our study.

Buffalo, kudu and warthog may be carriers of zoonotic diseases such as bovine tuberculosis (Michel et al., 2006) and brucellosis (Bengis, 2005). These can potentially be transmitted to livestock and humans, and are of particular concern in immuno-compromised humans, such as HIV positive patients. Considering that the HIV prevalence in South Africa is one of the highest in Africa (Maher et al., 2005) and that the prevalence in Mpumalanga Province, just outside the KNP, is among the highest in the world (Shisana et al., 2009) the presence of wildlife species able to transmit zoonotic pathogens in communal areas adjacent to the KNP is a public health concern (Michel et al., 2006).

To mitigate the problem of wildlife crossings in communal areas, DAFF has recently begun erecting a new reinforced fence that is not dependent on electricity to be functional. This new fence, which seems to be efficient in keeping elephants and large mammals within the park, will progressively replace the damaged electric fence in area A, starting at in the north of KNP (Punda Maria), at a rate of $25 \mathrm{~km} / \mathrm{year}$; it unfortunately, at the time of this study, its length was still too short $(13 \mathrm{~km})$ to be assessed by our questionnaire. However, future studies should be able to evaluate the success of this new fence, which shows promising results in keeping large mammals such as elephants and buffaloes within the KNP(D. Keet, pers. comm.).

The quantitative data on wildlife observations collected by our questionnaire method need to be interpreted with caution since observations can be subjected to recall bias, or biased towards certain animal species that are the main cause of damage and repair work (i.e., elephants). Recall bias could have played a role in the quantification of wildlife observations, which were estimated retrospectively by season and were not the result of a systematic 
record keeping procedure. In addition, it is also possible that some teams of fence workers could have exaggerated elephant damage and presence in order to justify their work and level of performance. Bias in estimates of animal observations may also have occurred in some sections due to the teams' perception that they were being evaluated, or because more than one fence team observed the same animal or group of animals moving along the fence.

The implementation of prospective, spatially explicit record keeping methods to record fence events should reduce error in recall and allow the compilation of more accurate quantitative data. A first attempt to implement such a method has provided promising results in the north of the KNP and further implementation of this method has been planned for the near future. Another approach for reducing bias could be to implement the questionnaire on a routine basis, for example once or twice per season.

Negative binomial regression was used to model the wildlife estimated figures in this study because initial attempts to use Poisson regression had showed significant lack of fit. The highly significant overdispersion parameters and the non-significant goodness-of-fit tests for the negative binomial models suggested that they were indeed more appropriate than Poisson models and, despite the small sample size, they yielded biologically plausible results. However, considering the high proportion of zero observations recorded, it may be that zero-inflated models would be more appropriate; but their use would require larger numbers of observations.

Although the number of questionnaires completed in this study was low $(n=32)$, information was gathered from $90 \%$ of the fence under the management of DAFF. This public fence represents approximately $70 \%$ of the western boundary fence, the remainder being managed by private or provincial game reserves adjacent to the KNP (Fig. 1). In the case of privately owned game reserves, the fence is generally well maintained and electricity is functional. It can therefore be anticipated that fence efficiency is high and very similar to that observed in area $C$.

Despite the limitations in sample size and possible sources of bias, it should be noted however, that considerable differences were found in most of the outcomes measured, statistical significance was achieved in many cases, and the results were biologically plausible. This suggests that the questionnaire based evaluation method presented here is a valuable method to assess the efficiency of physical barriers used to confine wildlife in protected areas and veterinary cordon fences in Southern Africa.

\section{Conclusion}

The questionnaire methodology presented here gives a good overview of the relative frequency of different large mammal species crossing the KNP fence, the main areas where permeability occurs and suggests a possible effect of the damage induced by elephants on the movement of the other species. Despite its potential weaknesses, the questionnaire method has provided plausible information that makes ecological sense when compared with published literature. Among the different wildlife species assessed, elephant was identified as the main species crossing the fence and a major cause of fence damage, particularly in the absence of regular fence maintenance. Equally, elephant induced damage seems to contribute to the exit of other wildlife species from the KNP. This suggests that, with the progressive growth of elephant populations in the KNP (Lange, 2008) and in other protected areas of Southern Africa (NNF, 2005), pressure on veterinary control fences will increase, challenging the effective separation of wildlife and livestock. The implementation of a rapid and cost-effective methodology for routinely monitoring fence effectiveness in Southern Africa may be needed in order to test the efficiency of improved physical barriers, and in order to identify high risk areas of contact between wildlife and livestock that may require more specific or intensive disease surveillance methods or control strategies.

\section{Acknowledgements}

We would like to acknowledge the support of Dr. Roy Bengis and Dr. Dewald Keet, from the Directorate of Veterinary Services in the KNP, for facilitating access to the fence camps. We are also very grateful to the technicians R.D. Makondo and P. Baloyi for their translation and logistic support. We would equally like to thank Dr. B. Du Plessis, Deputy Director of Animal Health and Dr. O. Rikhotso from the National Veterinary Services in Mpumalanga Province for their local support in the region. The same applies for Dr. Edwin Dyasson in the Limpopo Province. A very special acknowledgement is given to all the fence personnel for their cooperation and hospitality. This work was funded by a post-doctoral fellowship from the University of Pretoria and the CORUS Project "Development of an epidemiological network for monitoring the dynamics of Foot and Mouth Disease within the GLTFCA" funded by the French Ministry of Foreign Affairs.

\section{References}

Anderson, E.C., Foggin, C., Atkinson, M., Sorensen, K.J., Madekurozva, R.L., Nqindi, K.J., 1993. The role of wild animals other than buffalo in the current epidemiology of foot and mouth disease in Zimbabwe. Epidemiol. Infect. 11, 559-563.

Bengis, R., 2005. Transfrontier conservation area initiatives in sub-Saharan Africa: some animal health challenges. In: Osofsky, S.A. (Ed.), Conservation and Development Interventions at the Wildlife/Livestock Interface: Implications for Wildlife, Livestock and Human Health. Occasional Paper IUCN SSC, Gland, Switzerland/Cambridge, UK, pp. 15-19.

Brahmbhatt, D.P., Fosgate, G.T., Dyason, E., Gummow, B., Jori, F., Budke, C., Srinivasan, R., Ward, M.P., 2009. Contacts between wildlife and livestock at the Kruger National Park Interface of the Republic of South Africa. In: 12th International Symposium on Veterinary Epidemiology and Economics, Durban, South Africa.

Gadd, M.E., 2002. The impact of elephants on the marula tree Sclerocarya birrea. Afr. J Ecol. 40, 328-336.

Grant, R., Bengis, R., Balfour, D., Peel, M., 2008. Controlling the distribution of elephants. In: Scholes, R.J., Menell, K. (Eds.), A Scientific Assessment of Elephant Management in South Africa. Witwatersrand University Press, Johannesburg, South Africa, pp. 329-369.

Hargreaves, S.K., Foggin, C.M., Anderson, E.C., Bastos, A.D.S., Thomson, G.R., Ferris, N.P., Knowles, N.J., 2004. An investigation into the source and spread of foot and mouth disease virus from a wildlife conservancy in Zimbabwe. Rev. Sci. Tech. OIE 23, 783-790.

Jori, F., Vosloo, W., Du Plessis, B., Bengis, R.G., Brahmbhatt, D., Gummow, B., Thomson, G.R., 2009. A qualitative risk assessment of factors contributing to foot and mouth disease cattle outbreaks along the western boundary of Kruger National Park. Rev. Sci. Tech. OIE 28, 917-933. 
Kloeck, P.E., 1998. Tuberculosis of domestic animals in areas surrounding the Kruger National Park. In: Proceedings of the Challenges of Managing Tuberculosis in Wildlife in Southern Africa, Zunkel, July 30-31, Nelspruit, South Africa.

Lange, K., 2008. Elephant Management, National Geographic Magazine Website. http://ngm.nationalgeographic.com/2008/09/elephantmanagement/lange-text/1 (accessed 18.01.11.).

Latif, A.A., Hove, T., Kanhai, G.K., Masaka, 2002. Buffalo associated Theileria parva: the risk to cattle of buffalo translocation into the Highveld of Zimbabwe. Ann. N. Y. Acad. Sci. 969, 275-280.

Letshwenyo, M., Mapitse, N., Hyera, J.M.K., 2006. Foot-and-mouth disease in a kudu (Tragelaphus strepsiceros) in Botswana. Vet. Rec. 159, 252-253.

Maher, D., Harries, A., Getahun, H., 2005. Tuberculosis and HIV interaction in sub-Saharan Africa: impact on patients and programmes; implications for policies. Trop. Med. Int. Health 10, 734-742.

Martin, R.B., 2005. The influence of veterinary control fences on certain wild large mammal species in the Caprivi strip, Namibia. In: Ososfsky, S.A. (Ed.), Conservation and Development Interventions at the Wildlife/Livestock Interface: Implications for Wildlife, Livestock and Human Health. Occasional Paper IUCN SSC, Gland, Switzerland/Cambridge, UK, pp. 27-39.

Michel, A.L., Bengis, R.G., Keet, D.F., Hofmeyr, M., De Klerk, L.M., Cross, P.C., Jolles, A.E., Cooper, D., Whyte, I.J., Buss, P., Godfroid, J., 2006. Wildlife tuberculosis in South African conservation areas: implications and challenges. Vet. Microbiol. 112, 91-100.

Namibian Nature Foundation Webpage, 2005. Elephant-NumbersNeighbours. IRAS, http://www.nnf.org.na/RARESPECIES/InfoSys/ elephant/numbers/La_neighbours.htm (accessed 18.01.09.).

O'Conell-Rodwell, C., Rodwell, T., Rice, M., Hart, L.A., 2000. Living with modern conservation paradigm: can agricultural communities coexist with elephants? A five year study in East Caprivi, Namibia. Biol. Conserv. 93, 381-391.

Okello, M.M., D’Amour, D.E., 2008. Agriculturalexpansion within Kiùmana electric fences and implications for natural resource conservation around Amboseli National Park, Kenya. J. Arid Environ. 72, 2179-2192.
Potgieter, F.T., Stoltsz, W.H., Blouin, E.F., Roos, J.A., 1988. Corridor disease in South Africa: a review of the current status. J. S. Afr. Vet. Assoc. 59, 155-160.

Schumann, M., Schumann, B., Dickman, A., Watson, L.H., Marker, L., 2006. Assessing the use of swing gates in game fences as a potential nonlethal predator exclusion technique. S. Afr. J. Wild Res. 36, 173-181.

Shisana, O., Rehle, T., Simbayi, L.C., Zuma, K., Jooste, S., Pillay-van-Wyk, V., Mbelle, N., Van Zyl, J., Parker, W., Zungu, N.P., Pezi, S., the SABSSM III Implementation Team, 2009. South African National HIV Prevalence, Incidence, Behaviour and Communication Survey 2008: A Turning Tide Among Teenagers? HSRC Press, Cape Town.

Sutmoller, P., Thomson, G.R., Hargreaves, S.K., Foggin, C.M., Anderson, E.C., 2000. The foot-and-mouth disease risk posed by African buffalo within wildlife conservancies to the cattle industry of Zimbabwe. Prev. Vet. Med. 44, 43-60.

Sutmoller, P., 2002. The fencing issues relative to the control of foot and mouth disease. Ann. N. Y. Acad. Sci. 969, 191-200.

Thomson, G.R., 1999. Alternatives for controlling animal diseases resulting from interactions between livestock and wildlife in Southern Africa. S. Afr. J. Sci. 95, 71-76.

Thomson, G.R., Vosloo, W., Bastos, A.D.S., 2003. Foot and mouth disease in wildlife. Virus Res. 91, 145-161.

Thouless, C.R., Sakwa, J., 1995. Shocking elephants: fences and crop raiders in Laikipia District, Kenya. Biol. Conserv. 72, 99-107.

Vosloo, W., Bastos, A.D.S., Boshoff, C.I., 2006. Retrospective genetic analysis of SAT-1 type foot-and-mouth disease outbreaks in southern Africa. Arch. Virol. 151, 285-298.

Vosloo, W., Boshoff, C.I., Dwarka, R.M., Bastos, A.D.S., 2002. The possible role that buffalo played in the recent outbreaks of foot-and-mouth disease in South Africa. Ann. N. Y. Acad. Sci. 969, 187-190.

Vosloo, W., Thomson, G.R., 2004. Natural habitats in which foot and mouth disease viruses are maintained. In: Sobrino, F., Domingo, E. (Eds.), Foot-and-Mouth Disease: Current Perspectives. Great Britain, Horizon Bioscience, pp. 383-410.

Vosloo, W., Thompson, P.N., Botha, B., Bengis, R.G., Thomson, G.R., 2009. Longitudinal study to investigate the role of impala (Aepyceros melampus) in foot-and-mouth disease maintenance in the Kruger National Park, South Africa. Transbound. Emerg. Dis. 56, 18-30. 